\section{RISK FACTORS FOR MATERNAL MORTALITY IN DELHI SLUMS: A COMMUNITY-BASED CASE-CONTROL STUDY}

ABHA AGGARWAL, ARVIND PANDEY, B. N. BHATTACHARYA*

\section{ABSTRACT}

BACKGROUND: In order to develop, implement and evaluate policy for reducing maternal mortality, it is essential to study the risk factors associated with maternal deaths. AIMS: The study aims to determine the epidemiological risk factors and its related causes associated with maternal deaths in Delhi slums. MATERIALS AND METHODS: A community-based case-control study was designed, wherein snowball-sampling method was used to identify the maternal deaths (cases) in the community, and circular systematic random sampling procedure was used to select the controls from the same area where a maternal death was found STATISTICAL ANALYSIS: Data on 70 cases and 384 controls that had live births as the outcome of the pregnancy were analyzed. Logistic regression was applied to identify the risk factors. RESULTS: In the study population, most of the deliveries were conducted at home by untrained 'dais.' Cases were mostly illiterate, young, having high parity and no antenatal care taken during pregnancy $(P<0.05)$ as compared to controls. The distance of health facility from residence was also found to be a significant risk factor for maternal death $(P<0.05)$. Complications during pregnancy, like jaundice, excessive bleeding and anemia, were also found to be significant. The major causes of materna death were found to be hemorrhage after delivery, retained placenta and anemia. CONCLUSIONS: The study findings suggest that women should be educated about the importance of antenatal registration and regular checkups. Untrained 'dais' should be trained to recognize the obstetric complications at an early stage and refer high-risk cases for adequate management. These preventive measures could help in reducing maternal mortality at the community level.

(

Key words: Case control study, maternal mortality, risk factors, snowball sampling 2

Pregnancy complications and childbirth-related complications are the major causes of death among women in their reproductive ages.

National Institute of Medical Statistics, Indian Council of Medical Research, New Delhi, " Indian Statistica Institute, Kolkata, India

\section{Correspondence:}

Dr. Abha Aggarwal, AD,

National Institute of Medical Statistics (ICMR), Ansari Nagar, New Delhi, India. E-mail: aabha54@ rediffmail.com electricity.
Although various safe motherhood initiatives have been taken, yet decline in materna mortality ratio (MMR: defined as materna deaths per 100,000 live births) in India is far from the desired level of 100 by 2012 set by the National Rural Health Mission (NRHM) and 109 by 2015 as per millennium development goals (MDG). The level of MMR in India has declined from over 750 in the sixties to about 400 in the nineties. ${ }^{[2-3]}$ Recent round of sample registration system has estimated the level of MMR in India to be about 300 in 2001-03. However, the level of MMR is above 400 in some of the states ${ }^{[4-5]}$ encompassing over $40 \%$ of India's population. This invites the attention of researchers to examine the causes and epidemiological factors associated with maternal deaths. In the past, there have been some studies which have identified adolescent pregnancy, short interval between pregnancies, multi-parity and distance from referral hospitals as the bio-behavioral risk factors. ${ }^{[6-9]}$ However, these studies are mostly descriptive and conducted in hospitals. Since majority of the deliveries in India are conducted by traditional birth attendants (TBAs), hospitalbased estimates may not reveal the rea picture. In the populations where obstetric care is poor and the lifetime risk of materna death is much higher, it is essential to study the specific causes of such maternal deaths. In addition, abortion-related maternal deaths are often not accounted by these studies. Such issues are significantly prevalent in slums and underserved populations. In this context, a community-based case-control study was designed in Delhi slums* to determine the epidemiological risk factors of maternal deaths and their related causes. Further, the relative importance of each of these factors has been estimated by determining its relative risk through odds ratio using logistic regression analysis.

\section{MATERIALS AND METHODS}

This study was a community-based case control study, wherein a 'case' was defined as a woman who was pregnant and whose pregnancy's outcome was a live birth but the woman died within 42 days of delivery. A control was defined as a woman who was pregnant and whose pregnancy's outcome was a live birth and the woman was surviving at the time of survey. c

Out of a total of 929 designated slums in Delhi the study was conducted amongst 328 slums where the eighth India Population Project (IPP VIII) was implemented. The population of these slums was approximately 1.25 million. This population was catered by 21 health centers, 6 maternity homes and 105 heath posts. A maternity home covered a population of 2 million; and for every 50,000 population, there was one health center and for every 10,000 population one health post was created. ${ }^{[10}$ These health centers were visited to capture the information regarding maternal deaths. The information of maternal deaths that occurred during the reference period, viz., April 2000 March 2003, was collected from the registers maintained at health centers. In addition to this, snowball-sampling method was used to capture all the maternal deaths in the community. ${ }^{[5]}$ infections and disabilities during pregnancy or childbirth. This means, at least 10 million women incur this type of damage every year. ${ }^{[1]}$

*A slum may be defined as a thickly populated area with no planned structure for toilet facilities, drinking water and

\section{Snowball sampling for the selection of} cases

Snowball-sampling technique identifies households where maternal deaths had occurred, through some key informants, viz., 
antenatal nurse midwife (ANM) or Basti Sevika in the slum, by asking each of them to identify the households where maternal deaths had occurred. Having prepared the list of such households, a field investigator visits such households and gathers information about the event (maternal death) from a respondent (husband/mother-in-law/near relative) and then gathers the name of other households where a similar event (maternal death) had occurred and so on. By this method, all the maternal deaths are covered by contacting a few related households in the community. This method makes use of quick compilation of maternal deaths. ${ }^{[5]}$

\section{Data collection}

A well-designed pre-tested questionnaire was used to collect the detailed information on cases and controls. The pre-testing of the questionnaire was done in one of the slums of Delhi, namely, Nehru Place, in January 2003. Data was collected for cases and controls by the principal investigator herself, and the necessary modifications and additions to the questionnaire were made based on the experience of pretesting after discussion in the expert group meeting. Three types of variables, viz., socioeconomic, biological and environmental, were considered in the questionnaire. The socioeconomic variables included type of house, type of family, separate kitchen, type of toilets, woman's education, husband's education, etc. The biological variables considered were current age; age at marriage; parity; and various complications during pregnancy, such as anemia, fever, jaundice, excessive bleeding and abnormal presentation of child. Environmental factors included utilization of health facilities that consist of antenatal care (ANC), delivery care; and the distance of residence from the health facility. The details and history of all the maternal deaths were collected through verbal autopsy conducted by trained interviewers. The gynecologist, on the basis of information recorded through verbal autopsy, assigned the cause of maternal death. The causes of maternal deaths were classified as direct or indirect. Direct cause of maternal deaths refers to diseases and complications that occur only during pregnancy (e.g., postpartum hemorrhage, obstructed labor, etc.), and indirect causes are diseases that may be present before pregnancy but aggravated by pregnancy (e.g., anemia, heart disease, tuberculosis, etc.).

\section{Study population}

While a total of 131 cases and 393 controls were selected for the study, for comparative reasons, only those cases and controls whose outcome of pregnancy was live birth were included in this article. There were 70 cases where the outcome of pregnancy was a live birth but the mother died. The remaining cases were excluded from the study as the outcome of pregnancy was either stillbirth or abortion. Out of 393 controls, 384 controls in whom the the outcome of pregnancy was a live birth were included in this analysis. There were 9 controls in whom the outcome of pregnancy was stillbirth and hence were not included in this analysis.

\section{Circular systematic random sampling for}

\section{selection of controls}

To increase the power of the study, three controls were selected for each case through circular systematic random sampling, from the same area where a maternal death had occurred. For this, the total number of households was divided by the number of controls to be selected in that area, i.e., three times the cases found in a particular area, called an interval (say k); then every $\mathrm{k}^{\text {th }}$ household where a live birth occurred during the reference period with surviving mother was selected as a control.

\section{Statistical analysis}

Two-sample test for testing the difference ( $Z$ statistic) between the proportions was applied to the various categories of variables and any $P$-value $<0.05$ was considered significant. Univariate logistic regression analysis was applied to various significant variables to identify the risk factors associated with maternal deaths. The significant variables were classified into two categories, severe and normal. Severe category was coded as 1 and normal category was coded as 0 . The normal category was taken as reference category for comparison of various variables between cases and controls. The relative risk was estimated by odds ratio along with its $P$-value and confidence limits. Similarly, multivariate logistic regression models were estimated to see the joint effects of various complications that occurred during pregnancy and delivery. Hosmer and Lemeshow test has been used to test the goodness of fit of the model under the assumption that the best fit model was not different from the perfect model. It follows a Chi-square distribution with one degree of freedom. SPSS software version 12.0.1 was used for analyzing the data.

\section{RESULTS}

As mentioned, the results are presented for 70 cases and 393 controls. It was found that major causes for maternal deaths were anemia and hemorrhage after delivery (PPH)
(21.4\% each), retained placenta (17.2\%) and sepsis $(11.4 \%)$. The analysis revealed that 43 $(61.4 \%)$ maternal deaths occurred due to direct causes and 27 (38.6\%) due to indirect causes, which included 15 maternal deaths $(55.5 \%)$ due to anemia. Other indirect causes included jaundice, TB, respiratory disorder and suicide. About $9 \%$ of the cases developed postoperative complications, and about $1 \%$ had obstructed labor [Table 1]. No significant difference was found in household characteristics, viz., typ of house, number of rooms, type of toilets electricity, etc., in cases and controls, indicating that they were similar [Table 2]. About $77 \%$ of cases were illiterate as compared to $61 \%$ in controls $(P<0.001)$. The age of $79 \%$ of cases and $75 \%$ of controls at marriage was between 15 and 19 years $(P>0.05)$. More than $65 \%$ of controls were living in nuclear families; while in cases, it was about $57 \%(P=0.03)$. Agains $28 \%$ cases, $14 \%$ controls had parity $2(P=$ 0.017 ) [Table 3]. A significant proportion, $23 \%$ of cases, did not register for ANC as compared to $9 \%$ in controls $(P<0.001)$. Further, more than $60 \%$ of maternal deaths occurred in those households who lived $>5 \mathrm{~km}$ away from a health facility $(P<0.001)$. To reach the health facility, the mode of transport used by the women included walking, manual rickshaw, auto

Table 1: Causes of maternal deaths $(\mathbf{n}=70)$

\begin{tabular}{lcc}
\hline Causes of maternal death & Number & $\%$ \\
\hline Direct causes & & \\
PPH & 15 & 21.4 \\
Retained placenta & 12 & 17.2 \\
Sepsis & 8 & 11.4 \\
Obstructed labor & 1 & 1.4 \\
Embolism & 1 & 1.4 \\
Indirect causes & 15 & 21.4 \\
Anemia & 6 & 8.6 \\
Postoperative & 12 & 17.2 \\
Other causes & \\
Total & 70 & 100.0 \\
\hline${ }^{*}$ Other causes include jaundice, TB, respiratory disorder and
\end{tabular}

suicide. 
Table 2: Household characteristics of the study population

\begin{tabular}{|c|c|c|}
\hline Characteristics & $\begin{array}{c}\text { Case (\%) } \\
n=70\end{array}$ & $\begin{array}{c}\text { Control (\%), } \\
n=384^{\prime \prime}\end{array}$ \\
\hline \multicolumn{3}{|l|}{${ }^{*}$ Type of house } \\
\hline Kutcha & $17(24.3)$ & $73(19.0)$ \\
\hline Pucca & $22(31.4)$ & $122(31.8)$ \\
\hline Semi Pucca & $31(44.3)$ & 189 (49.2) \\
\hline \multicolumn{3}{|c|}{ Number of rooms in the house } \\
\hline & $47(70.0)$ & $236(61.5)$ \\
\hline 2 & $11(15.7)$ & $93(24.2)$ \\
\hline 3 & $10(14.3)$ & $55(14.3)$ \\
\hline \multicolumn{3}{|l|}{ Separate kitchen } \\
\hline & $12(17.1)$ & $87(22.7)$ \\
\hline No & $58(82.9)$ & $297(77.3)$ \\
\hline \multicolumn{3}{|l|}{ Type of toilet } \\
\hline open area & $26(37.1)$ & $138(35.9)$ \\
\hline own flush toilet & $4(5.7)$ & $46(12.0)$ \\
\hline own pi & $11(1$ & $49(12.8)$ \\
\hline${ }^{* *}$ Other & $29(41.4)$ & 29 (41.4) \\
\hline \multicolumn{3}{|c|}{ Electricity in the house } \\
\hline Yes & $67(95.7)$ & 374 (97.4) \\
\hline No & $3(4.3)$ & $10(2.6)$ \\
\hline \multicolumn{3}{|c|}{ Source of drinking water } \\
\hline Well & $2(2.9)$ & \\
\hline Hand pump & $10(14.3)$ & $50(13.0)$ \\
\hline Tap water & $58(82.9)$ & $325(84.6)$ \\
\hline \multicolumn{3}{|l|}{ Cooking fuel used } \\
\hline Cow dung cakes & $1(1.4)$ & $6(1.6)$ \\
\hline Fire wood & $3(4.3)$ & $15(3.9)$ \\
\hline Coal/coke & $3(4.3)$ & $27(7.0)$ \\
\hline Kerosene & $39(55.7)$ & $167(43.5)$ \\
\hline LPG & $17(24.3)$ & $141(36.7)$ \\
\hline Others & $2(2.9)$ & $0(0.0)$ \\
\hline Multiple & $5(7.1)$ & $28(7.3)$ \\
\hline
\end{tabular}

Mutcha house is a hut or a house built of bricks with temporay roof. *Pucca house is a permanent structure. *Semi Pucca house is a temporary house built of brick, cement and having asbestos roof. **'Others' include sulabh system, which is a combined flush toilet system provided for a slum. This facility is provided by the Municipal Corporation of Delhi. All variable are nonsignificant $(P>0,05)$

rickshaw and taxi/van. Significant differences were found between cases and controls in using the manual rickshaw / auto rickshaw as the means of transport $(P<0.001)$. Home delivery was observed in $55.7 \%$ of cases and $69.8 \%$ of controls, while institutional delivery took place in $44.3 \%$ of cases and $30.2 \%$ of controls $(P=0.02)$ [Table 4]. Complications encountered during pregnancy varied and included anemia, high blood pressure, fever, jaundice, abnormal presentation of child, excessive bleeding during delivery, retained placenta $(P<0.001)$. However, no significant
Table 3: Socioeconomic and reproductive characteristics of the study population

\begin{tabular}{|c|c|c|c|}
\hline Variables & $\begin{array}{c}\text { Case (\%) } \\
\mathrm{n}=70\end{array}$ & $\begin{array}{c}\text { Control (\%) } \\
n=384\end{array}$ & $P$ value \\
\hline \multicolumn{4}{|l|}{ Caste } \\
\hline $\mathrm{sc} / \mathrm{S}$ & $40(57.1)$ & $189(49.2)$ & NS \\
\hline Othe & $7(1$ & & NS \\
\hline Genera & $23(32.9)$ & $136(35.4)$ & NS \\
\hline \multicolumn{4}{|l|}{ Education level } \\
\hline Illiterate & $54(77.1)$ & $234(60.9)$ & 0.005 \\
\hline Literate & $16(22.9)$ & $150(39.1)$ & NS \\
\hline \multicolumn{4}{|l|}{ Husbar } \\
\hline Illiter & $31(44.3)$ & $113(29.5)$ & 0.007 \\
\hline $\begin{array}{l}\text { Literate } \\
\text { Type of fa }\end{array}$ & $39(55.7)$ & $271(70.5)$ & NS \\
\hline $\begin{array}{l}\text { Nuclear } \\
\text { Joint }\end{array}$ & $40(57.1)$ & $262(68.2)$ & 0.03 \\
\hline \multicolumn{3}{|c|}{$(1)$} & \\
\hline $15-1$ & $4(5.7)$ & 9 (2.3) & NS \\
\hline 20-24 & $18(25.7)$ & $111(28.9)$ & NS \\
\hline & $19(27.1)$ & $162(42.4)$ & NS \\
\hline & $16(22.9)$ & 75 (19.5) & NS \\
\hline$\geq 35$ & $13(18.6)$ & $26(6.8)$ & 0.0006 \\
\hline \multicolumn{4}{|l|}{ Age at marriage of woman } \\
\hline $15-19$ & $55(78.6)$ & $289(75.3)$ & NS \\
\hline & $12(17.1)$ & $73(19.0)$ & NS \\
\hline & $3(4.3)$ & $22(5.7)$ & NS \\
\hline & $14(20.0)$ & $68(17.7)$ & \\
\hline 2 & $10(14.3)$ & 106 (27.6) & 0.0107 \\
\hline & $14(20.5)$ & $87(22.7)$ & NS \\
\hline $4+$ & $32(45.7)$ & $123(32.0)$ & NS \\
\hline
\end{tabular}

VS - Nonsignificant $(P>0.05), P<0.05$-Significant variable.

difference was found between cases and controls in regard to high blood pressure and fever $(P>0.05)$. Among home deliveries, in cases $94.9 \%$ of the deliveries were conducted by untrained dais/elderly ladies; while in controls, $72.4 \%$ were conducted by untrained dais $(P<0.001)$. The study shows that $67.2 \%$ of maternal deaths occurred at a health institution, $25.7 \%$ maternal deaths occurred at home and $7.1 \%$ died on the way to a health facility. Of the $67.2 \%$ institutional deaths, about $49 \%$ maternal deaths occurred within $24 \mathrm{~h}$ (day 0 ) of delivery, $17 \%$ on day one, $10.6 \%$ on day two and $23.4 \%$ maternal deaths occurred after two days from the day of delivery [Table 5].

Univariate logistic regression analysis shows that the risk of dying of a woman in the
Table 4: Utilization of health facilities

\begin{tabular}{|c|c|c|c|}
\hline Variables & $\begin{array}{c}\text { Cases (\%) } \\
n=70\end{array}$ & $\begin{array}{c}\text { Controls (\%) } \\
n=384\end{array}$ & $P$ value \\
\hline \multicolumn{4}{|l|}{ Register for ANC } \\
\hline Yes & $54(77.1)$ & 349 (90.9) & NS \\
\hline No & $16(22.9)$ & $35(9.1)$ & 0.0004 \\
\hline \multicolumn{4}{|l|}{$\begin{array}{l}\text { *Received T.T. } \\
\text { injection }\end{array}$} \\
\hline & $54(78.3)$ & 344 (90.3) & NS \\
\hline & & $37(9.7)$ & 0.002 \\
\hline \multicolumn{4}{|l|}{$\begin{array}{l}{ }^{* *} \text { Consumed IFA } \\
\text { tablet }\end{array}$} \\
\hline$<100$ & $33(47.1)$ & $250(65.1)$ & 0.006 \\
\hline$\geq 100$ & $37(52.9)$ & 134 (34.9) & NS \\
\hline \multirow{2}{*}{\multicolumn{4}{|c|}{$\begin{array}{l}\text { Distance of the health } \\
\text { facility from residence }\end{array}$}} \\
\hline & & & \\
\hline$<5 \mathrm{~km}$ & $23(38.3)$ & 237 (80.9) & NS \\
\hline$>5 \mathrm{~km}$ & $37(61.7)$ & $56(19.1)$ & 0.00003 \\
\hline \multicolumn{4}{|l|}{$\begin{array}{l}\text { Mode of transport used } \\
\text { to reach the health } \\
\text { facility" }\end{array}$} \\
\hline By walking & $5(8.1)$ & $56(20.1)$ & 0.025 \\
\hline Manual Rickshaw & $5(8$. & $95(34.2)$ & $<0.0$ \\
\hline Auto Rickshaw & $41(66.1)$ & $85(30.6)$ & $<0.001$ \\
\hline & $11(17.7)$ & $40(14.4)$ & 0.504 \\
\hline \multicolumn{4}{|l|}{ Place of delivery } \\
\hline a & 36 & $268(69.8)$ & 0.02 \\
\hline Hospital & $31(44.3)$ & $116(30.2)$ & 0.02 \\
\hline
\end{tabular}
controls $P<0.05$ - Significant variable.

categories of age $\leq 20$ years and $>30$ years was more $(\mathrm{OR}=2.40 ; \mathrm{Cl}=1.43-4.03 ; P=$ 0.001). The risk for maternal death was higher among illiterate women $(\mathrm{OR}=2.16 ; \mathrm{Cl}=1.19$ 3.92; $P=0.011$ ) than among literate women. Similarly, the risk was twice in case of women who had either parity 1 or more than 4 as compared to women having parity 2 or 3 (OR $=1.94 ; \mathrm{Cl}=1.14-3.30 ; P=0.001)$. Further the risk of dying for a woman due to no ANC registration was about three times more as compared to those who had registered for ANC care [Table 6]. The risk of maternal death was higher where the distance of the health facility from the residence was $>5 \mathrm{~km}$ as compared to a distance $<5 \mathrm{~km}(\mathrm{OR}=6.81 ; \mathrm{Cl}=3.75-12.36$; $P=0.0001)$. Jaundice, excessive bleeding during delivery and abnormal presentation of child were also found to be the significant
Table 5: Complications during pregnancy and delivery in cases and controls

\begin{tabular}{|c|c|c|c|}
\hline Variables & $\begin{array}{c}\text { Case (\%) } \\
n=70\end{array}$ & $\begin{array}{c}\text { Control (\%) } \\
n=384\end{array}$ & $P$ value \\
\hline \multicolumn{4}{|c|}{ Complication during pregnancies Anemia } \\
\hline Yes & $33(47.1)$ & $27(7.0)$ & $<0.001$ \\
\hline No & $37(52.9)$ & $357(93.0)$ & NS \\
\hline \multicolumn{4}{|l|}{ High blood pres } \\
\hline $\begin{array}{l}\text { Yes } \\
\text { No }\end{array}$ & $3(4.3)$ & $4(1.0)$ & NS \\
\hline $\begin{array}{l}\text { No } \\
\text { Jaundice }\end{array}$ & \multicolumn{2}{|c|}{ Jaundice } & \\
\hline $\begin{array}{l}\text { Yes } \\
\text { No }\end{array}$ & $\begin{array}{r}6(8.6) \\
64(91.4)\end{array}$ & $\begin{array}{c}5(1.3) \\
379(98.7)\end{array}$ & $<0.001$ \\
\hline \multicolumn{4}{|l|}{ Fever } \\
\hline $\begin{array}{l}\text { Yes } \\
\text { No }\end{array}$ & $\begin{array}{l}13(18.6) \\
57(81.4)\end{array}$ & $\begin{array}{r}50(13.0) \\
334(87.0)\end{array}$ & $\begin{array}{c}0.1062 \\
N S\end{array}$ \\
\hline \multicolumn{4}{|c|}{$\begin{array}{l}\text { Abnormal presentation } \\
\text { of child }\end{array}$} \\
\hline $\begin{array}{l}\text { Yes } \\
\text { No }\end{array}$ & $\begin{array}{l}14(20.0) \\
56(80.0)\end{array}$ & $\begin{array}{c}20(5.2) \\
364(94.8)\end{array}$ & $\begin{array}{l}<0.001 \\
\text { NS }\end{array}$ \\
\hline \multicolumn{4}{|c|}{$\begin{array}{l}\text { Complications during delivery } \\
\text { Excessive bleeding } \\
\text { during delivery }\end{array}$} \\
\hline $\begin{array}{l}\text { Yes } \\
\text { No } \\
\text { Retained placenta }\end{array}$ & $\begin{array}{r}5(7.1) \\
65(92.9)\end{array}$ & $\begin{array}{c}2(0.5) \\
382(99.5)\end{array}$ & $\begin{array}{l}<0.001 \\
\text { NS }\end{array}$ \\
\hline $\begin{array}{l}\text { Retaned placenta } \\
\text { Yes } \\
\text { No }\end{array}$ & $\begin{array}{c}5(7.1) \\
65(92.9)\end{array}$ & $\begin{array}{c}1(0.3) \\
383(99.7)\end{array}$ & $\begin{array}{l}<0.001 \\
\text { NS }\end{array}$ \\
\hline $\begin{array}{l}\text { Among the home } \\
\text { deliveries with live birtt } \\
\text { Delivery conducted by }\end{array}$ & & & \\
\hline Health $\mathrm{p}$ & $2(5.1)$ & 74( & NS \\
\hline $\begin{array}{l}\text { Untrained dai / elderly } \\
\text { woman }\end{array}$ & $37(94.9)$ & $194(72.4)$ & $<0.001$ \\
\hline Place of death & & & \\
\hline Hom & $18(25$. & & \\
\hline On the way & $5(7$. & & \\
\hline $\begin{array}{l}\text { Institutional } \\
\text { Number of days } \\
\text { woman stayed in the } \\
\text { hospital before death }\end{array}$ & $47(67.2)$ & & \\
\hline$<24 h$ & $23(48$ & & \\
\hline & $8(17$ & & \\
\hline Two days & $5(10.6)$ & & \\
\hline More than two days & $11(23.4)$ & & \\
\hline
\end{tabular}

$P<0.05$ indicates significant variable.

risk factors of maternal deaths. The risk fo maternal death was seven times more if delivery was conducted by an untrained da at home as compared to those conducted by health professionals $(\mathrm{OR}=6.87 ; \mathrm{Cl}=1.61$ 29.2; $P=0.009$ ) [Table 6]

Multivariate logistic regression model was used to see the joint effect of complications like anemia, jaundice, excessive bleeding during 
Table 6: Univariate logistic regression analysis

\begin{tabular}{|c|c|c|c|c|}
\hline Independent variables & Cases & Control & $O R(95 \% \mathrm{Cl}\}$ & $P$ value \\
\hline \multicolumn{5}{|l|}{ Current age } \\
\hline$\leq 20+\geq 30 \mathrm{yrs}$ & 38 & 127 & $2.40(1.43,4.03)$ & \multirow{2}{*}{0.001} \\
\hline $21-29$ yrs & 32 & 257 & 1.00 & \\
\hline \multicolumn{5}{|l|}{ Education of wife } \\
\hline Illiterate & 54 & 234 & $2.16(1.19,3.92)$ & \multirow[t]{2}{*}{0.011} \\
\hline & 16 & 150 & & \\
\hline \multicolumn{5}{|l|}{ Education of husband } \\
\hline Illiterate & 31 & 113 & $1.91(1.13,3.21)$ & \multirow{2}{*}{0.015} \\
\hline Literate & 39 & 271 & 1.00 & \\
\hline \multicolumn{5}{|l|}{ Type of family } \\
\hline Nuclear & 40 & 262 & $0.62(.286, .862)$ & \multirow[t]{2}{*}{0.013} \\
\hline Joint & 30 & 122 & 1.00 & \\
\hline \multicolumn{5}{|l|}{ Parity } \\
\hline 1 or 4 & 46 & 191 & $1.94(1.14,3.30)$ & \multirow[t]{2}{*}{0.015} \\
\hline 20 3 & 24 & 193 & & \\
\hline \multicolumn{5}{|l|}{ Whether ANC received } \\
\hline No & 16 & 35 & $2.95(1.53,5.70)$ & \multirow[t]{2}{*}{0.001} \\
\hline Yes & 54 & 349 & 1.00 & \\
\hline \multicolumn{5}{|c|}{ Distance of residence from health center } \\
\hline$\geq 5 \mathrm{~km}$ & 37 & 20 & $6.81(3.75,12.36)$ & \multirow[t]{2}{*}{0.0001} \\
\hline & 56 & Anemia & 1.00 & \\
\hline $\begin{array}{l}\text { Anemá } \\
\text { Yes }\end{array}$ & 33 & 27 & $11.79(6.40,21.72)$ & \multirow[t]{2}{*}{$<0.001$} \\
\hline & & & 1.00 & \\
\hline \multicolumn{5}{|l|}{ Jaundice } \\
\hline Yes & 6 & & $7.10(1.91,22.58)$ & \multirow[t]{2}{*}{0.003} \\
\hline No & & & 1.00 & \\
\hline \multicolumn{5}{|c|}{ Excessive bleeding during delivery } \\
\hline & & & $14.68(2.08,79.04)$ & \multirow[t]{2}{*}{0.006} \\
\hline \multirow{2}{*}{\multicolumn{5}{|c|}{$\begin{array}{l}\text { No } \\
\text { Abnormal presentation of child }\end{array}$}} \\
\hline & & & & \\
\hline Yes & & 20 & $4.55(2.17,9.52)$ & \multirow[t]{2}{*}{0.000} \\
\hline \multirow{2}{*}{\multicolumn{5}{|c|}{$\begin{array}{l}\text { No } \\
\text { Among home deliveries }\end{array}$}} \\
\hline & & & & \\
\hline Untrained dais & 37 & 94 & $6.87(1.61,29.2)$ & 0.009 \\
\hline Health Professional & & & & \\
\hline
\end{tabular}

$P<0.05$ indicates significant variable.

delivery, abnormal presentation of child and retained placenta on maternal deaths. The model was found to be a best fit model $\left(\chi_{(1)}^{2}=\right.$ $0.446 ; P=0.406$ ), indicating that the assumed hypothesis is accepted. Results show that the risk of maternal death was more among anemic women $(\mathrm{OR}=11.76 ; \mathrm{Cl}=6.09-22.71$; $P<0.001$ ). Similar risk was found in case of excessive bleeding during delivery as compared to women with normal bleeding. The risk of maternal mortality associated with retained placenta in the presence of other complications was $(\mathrm{OR}=41.92 ; \mathrm{Cl}=4.5-388.75 ; P=0.001)$. Abnormal presentation of child was also found

in study was conducted in the urban slums in Delhi to investigate the epidemiological risk factors associated with maternal mortality using a cost-effective snowball-sampling

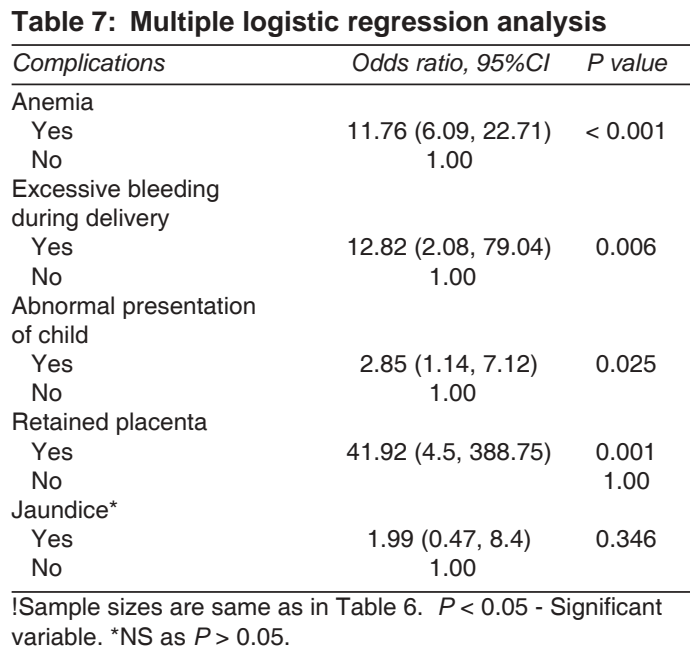
variable. ${ }^{*} \mathrm{NS}$ as $P>0.05$.

technique. ${ }^{[5,11]}$ The major direct causes of maternal death in the study were found to be $\mathrm{PPH}$, followed by retained placenta and sepsis. The data, particularly those of $\mathrm{PPH}$ and sepsis, are comparable to those reported elsewhere. ${ }^{[5,12,13]}$ However, as per the report of the sample registration system (SRS), hemorrhage has been reported to be $38 \%$, which is much higher than our estimate. Since SRS included all maternal deaths irrespective of the outcome of pregnancy, i.e., including abortions and stillbirths, against ours, which has considered only those maternal deaths where the outcome of pregnancy was only live birth; hence the former estimates are likely to be higher than ours. The estimates of sepsis were, however, comparable to our estimates..$^{[4]}$

Contrary to reported literature that hypertensive disorders are one of the causes of maternal deaths, ${ }^{[4]}$ our study did not find any such case, probably because the outcome of pregnancy included only live births. Also, our study was carried out in the slums of Delhi, where a large section of the pregnant women do not utilize the facility of ANC; and therefore, no case of hypertensive disorder was reported to have been included in the study. Further, the cause of death was elicited by the gynecologist through verbal autopsy after the death of the woman - based on the information collecte from family members, who may not have been aware of any hypertensive disease. The proportion of maternal deaths due to retained placenta in the present study wa found to be marginally higher than those reported elsewhere. ${ }^{[13]}$ In this context, it may be mentioned that as most of the deliveries were conducted at home, by untrained dais, they were unable to manage the cases that were even a little bit complicated. Retained placenta is potentially life threatening not only because of retention per se but also because of associated hemorrhage and infection, as well as complications related to its removal. These risks are increased in women in poor socia circumstances due to preexisting malnutrition anemia and unsupervised home deliveries. ${ }^{[14]}$

Among the indirect causes, anemia was found to be the major cause of maternal death in the present study. Our findings are consistent with those of other researchers who have reported that direct causes together with anemia are responsible for more than $65 \%$ of all maternal deaths in developing countries. ${ }^{[4]}$ Anemia remains a major problem among the women folk in India, and launch of the recent initiative of 'Twelve by Twelve (12 by 12),' if successful, would go a long way in not only reducing the maternal mortality but also maternal morbidity. ${ }^{[15]}$
Since the entire study population was from urban slums, wherein both cases and controls belonged to the same socioeconomic bracket 
with similar housing, water and toilet facilities, socioeconomic characteristics do not show statistically significant differences between cases and controls. Jaundice during pregnancy appears to be an important risk factor, which might have occurred due to poor sanitary conditions in and around the house. The study found that more maternal deaths occurred in younger women with high parity, living in joint families and with no ANC registration. The reason for not registering may be due to longer distance from the residence. Further, in joint families, pregnant women are more likely to be sidelined. It was found that among the home deliveries (39 cases), about $95 \%$ of the deliveries were conducted by untrained dais. Untrained dais are commonly sought after for conducting deliveries in rural and urban slum populations. Training them about safe delivery and immediate basic care of newborn infants and instructing them to refer to the nearest essential obstetric care unit if any danger signs become obvious may prove to be an important, cost-effective strategy to reduce maternal and neonatal mortality in communities. They can also contribute in terms of health education and encouraging breastfeeding. Investing in such training should be considered by policy makers and donor agencies. ${ }^{[16]}$ In our study, a high proportion of maternal deaths occurred in hospitals. A possible reason for such a paradoxical finding is that probably the deliveries were conducted at home by untrained dais and were rushed to a hospital at the last minute when they became too complicated for untrained dais to handle, and hence a greater number of women died at a hospital. This is also evident from the fact that most of the admitted women died within $24 \mathrm{~h}$ of admission (48.9\%).
CONCLUSION

Despite the many $\mathrm{MCH}$ programs in vogue, majority of cases had not even registered for ANC in the slum population and most of the deliveries were conducted at home by untrained dais. Preventive measures which could help to reduce maternal mortality include (1) mass education about the importance of antenatal registration and regular checkups and (2) more focus on training of dais. (3) Further, since the present study was conducted in the slums of Delhi, where institutional facilities and transport are more easily available than in the rural areas, women should be encouraged to go for institutional deliveries to reduce maternal mortality at the community level.

\section{ACKNOWLEDGEMENTS}

The authors are thankful to the Department of Family Welfare (Statistics Division), Ministry of Health and Family Welfare, GOI, for providing funds and entrusting this research study to National Institute of Medical Statistics. Thanks are also due to Dr. Mouha Maulik, Scientist, who helped in revising the manuscript. Mr. Jitendra Yadav and Mr. Ganesh Prasad Jenna are also duly thanked for conducting the field work.

\section{REFERENCES}

1. WHO, UNICEF and UNFPA, Maternal mortality in 2000. Estimates developed by WHO, UNICEF and UNFPA, Geneva. [Last updated on 2006 May]. Available from: http://www.childinfo.org/areas/ maternalmortality. [Last accessed on 2007 Jun 6].

2. Bhat PN, Navneetham K, Rajan SI. Maternal mortality in India: Estimates from a Regression Model. Stud Fam Plann 1995;26:217-32.

3. Bhat PN. Maternal mortality in India: An update.
Stud Fam Plann 2002;33:227-36.

4. Registrar General of India. Maternal Mortality in India: 1997-2003. Trends, Causes and Risk Factors. Registrar General India: New Delhi; Report. 2006. p. 1-29.

5. Singh P, Pandey A, Aggarwal A. House-to-house survey vs. snowball technique for capturing materna deaths in India: A search for a cost-effective method. Indian J Med Res 2007;125:550-6.

6. Thonneau P, Toure B, Cantrelle P, Barry TM, Papiernik E. Risk factors for maternal mortality: Results of a case-control study conducted in Conakry (Guinea). Int J Gynaecol Obstet 1992;39:87-92.

7. Kampikaho A, Irwig LM. Risk factors for maternal mortality in five Kampala Hospital. Int J Epidemiol 1990;9:1116-8.

8. Toure B, Thonneau P, Cantrelle P, Barry TM, Ngo-Khac T, Papiernik E. Level and causes of maternal mortality in Guinea [West Africa]. Int $\mathrm{J}$ Gynaecol Obstet 1992;37:89-95.

9. Anandalakshmy PN, Talwar PP, Buckshee K, Hihgorani V. Demographic, socio-economic and medical factors affecting maternal mortality: An Indian experience. J Fam Welfare 1995:39:1-4. 10. Institute for Research in Medical Statistics (ICMR),

\section{Author Help: Reference checking facility}

The manuscript system (www.journalonweb.com) allows the authors to check and verify the accuracy and style of references. The tool checks the references with PubM ed as per a predefined style. Authors are encouraged to use this facility before submitting articles to the journal.

- The style as well as bibliographic elements should be $100 \%$ accurate to get the references verified from the system. A single spelling error or addition of issue number / month of publication will lead to error to verifying the reference.

- Example of a correct style

Sheahan P, O'leary G, Lee G, Fitzgibbon J . Cystic cervical metastases: Incidence and diagnosis using fine needle aspiration biopsy. Otolaryngol Head Neck Surg 2002;127:294-8.

- Only the references from journals indexed in PubM ed would be checked.

- Enter each reference in new line, without a serial number.

- Add up to a maximum 15 reference at time.

- If the reference is correct for its bibliographic elements and punctuations, it will be show $n$ as CORRECT and a link to the correct article in PubMed will be given.

- If any of the bibliographic elements are missing, incorrect or extra (such as issue number), it will be shown as INCORRECT and link to possible articles in PubM ed will be given.
Ministry of Health and Family Welfare. End line Report 2003

11. Arora P. Maternal mortality: Indian scenario. 2003;28:43-6

Chat mortality . J reduced 0 bstet Gynaect be be Jun 15]

Banajeh S. Learning from low income countries: mortality in poor countries. BMJ 2005;330:478-9.

Source of Support: Nil, Conflict of Interest: None declared. 